\title{
Theoretical and numerical crush analysis of multi-stage nested aluminium alloy tubular structures under axial impact loading
}

\author{
TrongNhan Tran ${ }^{1,2 *}$, DucHieu Le ${ }^{3}$, Ahmad Baroutaji ${ }^{4 \dagger}$ \\ ${ }^{1}$ Division of Computational Mechatronics, Institute for Computational Science, Ton Duc Thang \\ University, Ho Chi Minh City, Vietnam. \\ ${ }^{2}$ Faculty of Electrical \& Electronics Engineering, Ton Duc Thang University, Ho Chi Minh City, Vietnam \\ ${ }^{3}$ Faculty of Automobile Technology, Hanoi University of Industry, VietNam \\ ${ }^{4}$ School of Engineering, Faculty of Science and Engineering, University of Wolverhampton, United \\ Kingdom
}

\begin{abstract}
In this paper, the crush behaviour and energy absorption performance of nested tubular thinwalled structures made of aluminium alloy under dynamic axial loading are investigated. Theoretical solutions for Average Crush Force $\left(P_{a c f}\right)$ of these structures are proposed by combining the energy method, simple superposition principle, and interaction among the various components of the structures. The derived theoretical models are verified by comparing their predictions with numerical and experimental values. The energy absorption indicators of the various structures are calculated and used to compare the various structures and to determine the best performing one. It is found that the nested structure with a higher number of tubes exhibits the best crashworthiness performance due to energy absorption enhancements resulted from the interaction effects between its components as well as its capability to reduce the peak crush force.
\end{abstract}

\footnotetext{
* Corresponding Author: Ton Duc Thang University, Ho Chi Minh City, Vietnam. E-mail: trantrongnhan@tdtu.edu.vn.

$\dagger$ Corresponding Author: School of Engineering, Faculty of Science and Engineering, University of Wolverhampton - United Kingdom. E-mail: ahmad.baroutaji2@mail.dcu.ie.
} 
Keywords: Axial loading; Impact; crashworthiness; Nested tubes; Theoretical analysis.

\begin{tabular}{|ll|}
\hline Nomenclature & \\
TSST & Tailored Single Square Tube \\
MNST2 & Multi Stage Nested Two-Square Tube \\
MNST3 & Multi-Stage Nested Three-Square Tube \\
MSSQ & Tailored Multi-Stage Square Tube \\
FE & Finite element \\
SSP & Simple Superposition Principle \\
MSSFE & Modified Simplified Super Folding Element \\
BFE & Basic Folding Element \\
$\mathrm{E}_{\mathrm{int}}$ & Internal energy \\
$\mathrm{E}_{\mathrm{b}}, \mathrm{E}_{\mathrm{m}}$ & Bending and membrane energy \\
$\mathrm{P}_{\mathrm{acf}}$ & Average collapsing load \\
$2 \mathrm{H}$ & Wavelength \\
$\eta$ & Effective crushed stroke \\
$\mathrm{M}_{0}$ & Fully plastic bending moment \\
$\mathrm{B}$ & Sum of side lengths \\
$\mathrm{b}$ & Side length \\
$\mathrm{t}$ & Wall thickness \\
$\sigma_{0}$ & Flow stress \\
$\sigma_{\mathrm{y}}, \sigma_{\mathrm{u}}$ & Yield strength and ultimate stress of material \\
$\mathrm{n}$ & \\
\hline
\end{tabular}




\section{Introduction}

For all types of passenger vehicles including automobiles, aircraft, trains and ships, energy absorbing components made of thin-walled tubes play a significant role in protecting occupants when the collision occurs [1]-[7]. Such tubes which are made of aluminium alloy can deform plastically in different modes, such as progressive buckling [8], [9], global bending [10], [11], inextensional (asymmetric) mode [12], and extensional (symmetric) mode [13], dissipating the impact energy and thus they improve the passive safety of the vehicle and protect the passengers. Among the various aforementioned collapse modes, the progressive buckling one has been continuously reported to have various advantages such as stable crush response and high energy absorption capacity [14]-[16].

In the recent years, new set of structural members known as multi-cell structures have been extensively studied as energy absorption components for their outstanding crashworthiness performance [17]-[20]. However, the multi-cell structures are not widely adopted for engineering applications due to their sophisticated cross sections which require high manufacturing cost and also due to high Peak Crush Force (PCF) associated with the crushing of these structures [2]. Compared with the multi-cell structures, the nested tubes structures are relatively easier to build energy absorbing components and capable of providing comparable crashworthiness performance. Many researchers have studied and analysed the crush behavior of the nested structures under lateral loading [21]-[24]. Morris et al. [21] analysed crash behaviour of the nested systems with side restraints and they found that using of the exterior restraint allowed the structure to absorb more energy. Olabi et al. [22], [23] optimised nested oblong and circular nested tubes systems under dynamic lateral loading. The findings of the researchers demonstrated that by introducing circular bar, the crushing response of the nested systems can be improved. Baroutaji et al. [24] carried out investigation on the collapse behaviour of the nested tube systems made of mild steel and found that under low velocity impact condition, strain rate has no significant impact on crash behaviour. The nested structures were also considered for axial loading case [25], [26]. Rahi [25], who studied the energy absorption behavior of combined bitubular tubes, reported that the specific energy absorption capacity of a combined bitubular tube is higher than those of individual square or circular tubes and it is also greater than the sum of their specific energy absorption capacities. Kashani et al. [27] introduced a new way to improve the crashworthy indicators of the square tubes under axial loading by using bitubal 
configuration. The results of this work showed that the nested tube structure's energy absorption ability is better than that of single tube under the same loading condition. Sharifi et al. [28] performed a study on the crushing response of the bitubular circular tubes. A similar conclusion with that in [27] was also delivered. Nia and Chahardoli [14], [15] performed investigations on the crashworthiness behavior of nested structures under axial loading and founded that the nested tubes structures offer higher specific energy absorption and crash force efficiency but lower stroke efficiency than the single tube.

The crush response of thin-walled tubes under axial loading is featured by an initial high Peak Crush Force (PCF) which might cause serious negative effects [2]. With the aim of diminishing the magnitude of PCF, crush initiator techniques such as corrugations [16], [29], holes [30], grooves [9], [31] are normally applied to thin-walled tubes. The crush initiator or triggers are not only reducing the PCF but also promoting the desirable deformation mechanism such as the progressive buckling. For example, Eyvazian et al. [29] showed the considerable influence of the corrugations on the collapse mode and energy absorption. The corrugated tube made the deformation of tube more controllable and improved the crashworthiness characteristics. Cheng et al. [30] experimentally investigated structure's crush behaviour with different types of crush initiators. The authors reported that introducing trigger into structure yielded lower peak crush force, higher specific energy absorption, and higher crush force efficiency. Najafi et al. [32] studied the influence of the trigger on structure's crush characteristics and they found that adding grooves can lower peak force and stabilise collapse mode of the structure. Shahi and Marzbanrad [33] presented another way to reduce peak crush force and enhance the performance of the energy absorber by using tailor cutting technique. The authors conducted studies on the crushing response of the tailor-made tube in which they found that the tube with tailor cutting has greater energy absorption ability than a tube with constant wall thickness. Overall, most of aforementioned crush initiator techniques involve altering the standard shape of the thin-walled structure and this means additional manufacturing costs. The nested tubes structures can provide a simple and cheap way to reduce the PCF by changing the length and stiffness of their components where the component with less stiffness can be made longer so it starts deforming before the other components yielding a lower PCF during the crushing process. However, the latter triggering method has only received limited attention in literature. 
Studies on energy absorption structures are normally conducted using experimental, numerical and theoretical techniques. The theoretical models that can describe the crush behaviour of a thin-walled structure are particularly important because they allow assessing the crashworthiness performance of the various structures quickly. Najafi and Rais-Rohani [31] expanded the super folding element theory [34] and an analytical solution of collapse response for a multi-corner tube under axial loading was proposed. Hanssen et al. [35] considered the behaviour of foam-filled square tubes. A formula of the average crush force for this structure is derived which included average crush force of the hollow tube, resistance of the foam, and interaction between tube and foam.

Despite the superior crashworthiness performance of nested tubes structures under axial loading, particularly those constructed from components with different stiffness, they have relatively received less attention in literature and no attempt was made before to develop theoretical models for evaluating the energy absorption behaviour of such structures in an efficient fashion. This paper aims to construct theoretical models of the nested structures based on the energy balance method, superposition principle and interaction among the structure's components. The effects of geometrical parameters and interaction between the components of the structure on its crashworthiness behaviour are discussed. Additionally, the advantages of adopting nested structures as energy absorption devices are highlighted by comparing their crashworthiness features with other types of structures such as tailored structures.

\section{Material and methods}

\subsection{Geometry and material properties}

In this study, three different thin-walled energy absorbing structures, namely as Tailor-cut Single Square Tube (TSST), Multi Stage Nested Two-Square Tube (MNST2), and Multi-Stage Nested Three-Square Tube (MNST3) were studied. The profiles of these structures are shown in Figure 1. The TSST structure employs trigger in the form of 16 circular holes which are distributed equally along the side length. Each hole has a diameter of $10 \mathrm{~mm}$ and placed at $10 \mathrm{~mm}$ below the top surface of TSST. The MNST2 consists of two square tubes with different sizes while the MNST3 have three square tubes with different dimensions arranged in a specific pattern to create nested systems. The inner tubes in MNST2 and MNST3 structures were longer than the other components and thus they act as crush initiators to decrease the initial peak force acting on the 
nested structures. Different configurations of MNST2 and MNST3 which vary from each other by the sizes of outer tubes were also considered in this paper to demonstrate the interaction effects between the various components of these structures. For comparison purposes, the energy absorption metrics of a structure called as tailor-cut multi-stage nested square tubes (MSSQ), which was presented by Zahran et al [36], were also calculated in this paper. All structures have the same weight and their geometrical parameters are presented in Table 2.

Aluminium alloy AA6061-O was used for all systems investigated in this work. The mechanical properties of the tubes' material are summarised in Table 1.

Fig. 1. Geometry of the studied structures: a) Tailored Single Square Tube (TSST), b) Multi Stage Nested Two-Square Tube (MNST2), c) Multi-Stage Nested Three-Square Tube (MNST3), and d) tailored multi-stage nested square tubes (MSSQ) [36] Table 1. Mechanical properties of Aluminium alloy AA6061-O [36] Table 2. Geometrical parameters of all structures

Fig. 2. FE model setup

\subsection{Finite Element Model}

Explicit FE code, LSDYNA, was used to build the finite element models of the three structures and to investigate their crashworthiness behaviour. The structures were meshed using Belytschko-Tsay shell element. The piecewise linear plastic material model was used to represent the structures' material, i.e. aluminium alloy AA6061-O. The structures were crushed between two surfaces which were modelled as rigid bodies. Automatic nodes to surface and automatic single-surface contacts were used for the contact between the structures and the rigid bodies and for the tube walls with each other, respectively. A friction coefficient of 0.28 is used in all contacts. The friction coefficient was selected as such neither interpenetration nor numerical instability are encountered during the solution [37]. The dynamic loading was simulated by a striker with a mass of $226 \mathrm{~kg}$ travelling at a velocity of $6.3 \mathrm{~m} / \mathrm{s}$ and impact at one end of the structure. A schematic of the finite element model setup is shown in Fig 2.

A mesh convergence investigation was performed to obtain the optimal mesh density for the finite element model. The convergence graph of five different mesh densities is shown in Fig. 3, which points out that an element size of $2 \mathrm{~mm}$ is able to produce a converged solution within a reasonable period of time. Thus, this mesh density is used in all subsequent finite element models in this work.

Fig 3. Convergence of force versus mesh density for square tube 


\section{Theoretical analysis}

In this section, theoretical relations of the average crush force $\left(P_{a c f}\right)$ are extracted for the structures undergoing axial crushing. The average collapsing load is normally estimated in an approximate way by equating the internal absorbed energy with the external work for a given collapse distance. The internal energy is determined by combining the Simple Superposition Principle (SSP) and Modified Simplified Super Folding Element (MSSFE) theory. In the MSSFE theory, the internal energy is a sum of the energy dissipated in membrane and bending deformations of a Basic Folding Element (BFE). The SSP indicates that the internal energy dissipated by a structure is the sum of all internal energy dissipated by all BFEs taken at the same time (Fig. 4). The internal energy dissipated in the deforming part of the structure is the sum of the energy dissipated in bending and membrane of the structure and then it can be expressed as

$$
E_{\mathrm{int}}=\sum_{i=1}^{n} E_{\mathrm{int}-i}=\sum_{i=1}^{n} E_{b-i}+\sum_{i=1}^{n} E_{m-i},
$$

where $n$ is the number of the BFEs in the structure. $E_{b-i}$ and $E_{m-i}$ are, respectively, the bending and membrane energy of the $i^{\text {th }}$ tube at a specific time. In the MSSFE theory, Basic Folding Element (BFE) encompasses triangular elements and plastic hinge lines as shown in Fig. 5.

Fig. 4. Simple superposition principle Fig. 5. Basic Folding Element (BFE): a) rotation angle $(\alpha=2 \pi)$ and plastic hinge line; b) extensional mode

Equating the work of external load to the internal energy dissipation gives

$$
P_{a c f} 2 H \eta=\left(\sum_{i=1}^{n} E_{b-i}+\sum_{i=1}^{n} E_{m-i}\right) \text {, }
$$

where $\eta$ is the stroke efficiency.

Most of the investigations proved that the wall of the folding after structure deformed can never be perfectly flattened as presented in Fig. 5. In this work, the value of $\eta$ is proposed to be 0.7 for all structures which falls within the range from 0.7 to 0.75 as suggested by other researchers for the stroke efficiency [34], [38], [39].

The energy absorption in bending of BFE element is evaluated by summing the energy dissipation at the plastic hinge lines. During collapsing, panels creating rotation angles are adopted to be entirely flattened, which displays the rotation angle $(\alpha)$ at plastic hinge lines of 
$2 \pi$ (Fig. 5a). Tube's angle element is formed by $m$ panels that have a similar role during the deformation. The bending energy for an angle element or a tube can be therefore estimated by the following formula

$$
E_{b}=2 \pi M_{0} \sum_{i=1}^{n}\left(B_{i}\right)
$$

where $M_{0}=\frac{\sigma_{0} t^{2}}{4}$ is the fully plastic bending moment of the panel, $B=\sum_{j=1}^{m} b_{j}$ is the sum of widths of all walls; $m$ is the number of the panel, $t$ is the wall thickness, $\sigma_{0}=\sqrt{\frac{\sigma_{y} \sigma_{u}}{1+n}}=89.49(\mathrm{MPa})$ is the flow stress of the material with power low hardening; $n=$ $0.19, \sigma_{y}=69.87(M P a)$, and $\sigma_{u}=136.4(M P a)$ are the yield and ultimate stress of the material, respectively.

The energy dissipation by membrane deformation of the BFE can be determined through extensional deformation mode at angle elements as shown in Fig. 5b. Based on superposition principle, this energy can be then calculated as follow

$$
E_{m}=\sum_{i=1}^{n}\left(\sum_{k=1}^{p} \int_{s_{k}} \sigma_{0} t_{k} d s_{k}\right)_{i}
$$

where $p$ is the number of the corner elements, and $s_{k}$ is the area of the membrane element at corners. For a corner element deformed in an extensional mode [40], its membrane energy can be calculated as

$$
E_{m}^{c e \_ \text {extensional }}=8 M_{0} \frac{H^{2}}{t} .
$$

in which, the membrane area at right corner element is $2 H^{2}$

\subsection{Extracting $\boldsymbol{P}_{\boldsymbol{a c f}}$ for TSST structure}

TSST contains four corner elements that are deformed in extensional mode under axial loading. Combining Eqs. (2), (3), and (5) yields the following relation

$$
P_{a c f}^{T S S T} 2 H \eta_{1}=E_{b}^{T S S T}+E_{m}^{T S S T}=2 \pi M_{0} B_{T S S T}+4\left(8 M_{0} \frac{H^{2}}{t}\right)
$$

or 
$\frac{P_{a c f}^{T S S T} \eta}{M_{0}}=\frac{\pi B_{T S S T}}{H}+16 \frac{H}{t}$

Based on the stationary condition $\left(\frac{\partial P_{m}}{\partial H}=0\right)$, the half- wavelength $(H)$ is calculated as follows

$H=\sqrt{\frac{\pi B_{T S S T} t}{16}}$

To replace $M_{0}=\frac{\sigma_{0} t^{2}}{4}$ and Eq. (8) into Eq. (6), the expression for $P_{a c f}$ of TSST is

$P_{a c f}^{T S S T}=\frac{1}{\eta}\left[\pi \frac{\sigma_{0} t^{2}}{4} B_{T S S T} \sqrt{\frac{16}{\pi B_{T S S T} t}}+16 \frac{\sigma_{0} t^{2}}{4} \frac{1}{t} \sqrt{\frac{\pi B_{T S S T} t}{16}}\right]$

Eq. (9) is rewritten in the form

$P_{a c f}^{T S S T}=\frac{1}{\eta}\left(2 \pi^{1 / 2} \sigma_{0} t^{3 / 2} B_{S S T}^{1 / 2}\right)$

in which $B_{T S S T}=(4 a-4 t)$

\subsection{Extracting $\boldsymbol{P}_{\boldsymbol{a c f}}$ for MNST2 structure}

MNST2 has two components including outer and inner tubes where each tube has four corner elements. Since the inner and outer tubes of the MNST2 structure have different sizes, their halfwavelengths during the deformation process are also different. However, it is assumed that both tubes have the same $\mathrm{H}$ but different membrane areas were assigned for each tube to consider the difference in the actual wavelengths. The membrane areas for inner and outer tubes are $2 \mathrm{H}^{2}$ and $2.5 \mathrm{H}^{2}$, respectively, which yield a membrane energy of $8 M_{0} \frac{H^{2}}{t}$ for inner tube and $10 M_{0} \frac{H^{2}}{t}$ for the outer tube. Substituting the expressions for $E_{b}$ and $E_{m}$ into Eq. (2) yields

$$
\begin{aligned}
P_{a c f}^{M N S T 2} 2 H \eta & =\left[E_{b}^{M N S T 2}+E_{m}^{M N S T 2}\right] \\
& =\left[2 \pi M_{0}\left(B_{1}+B_{2}\right)+4\left(8 M_{0} \frac{H^{2}}{t}+10 M_{0} \frac{H^{2}}{t}\right)\right]
\end{aligned}
$$

where $B_{1}$ and $B_{2}$ are the widths of inner and outer tubes, respectively; $t$ is the thickness of the tubes. The Eq. (11) is then rewritten as 


$$
\frac{P_{a c f}^{M N S T 2} \eta}{M_{0}}=\frac{\pi\left(B_{1}+B_{2}\right)}{H}+2\left(18 \frac{H}{t}\right)=\frac{\pi B_{M N S T 2}}{H}+36 \frac{H}{t}
$$

The wavelength of the folding $(H)$ is so far unknown but it can calculated from the stationary condition, i.e. $\frac{\partial P_{a c f}}{\partial H}=0$, which yields

$$
H=\sqrt{\frac{\pi B_{M N S T 2} t}{36}}
$$

By substituting Eq. (13) into Eq. (11), $P_{a c f}$ of the MNST2 can be obtained as

$$
P_{a c f}^{M N S T S}=\frac{1}{\eta}\left[\pi \frac{\sigma_{0} t^{2}}{4} B_{M N S T 2} \sqrt{\frac{36}{\pi B_{M N S T 2} t}}+32 \frac{\sigma_{0} t^{2}}{4} \frac{1}{t} \sqrt{\frac{\pi B_{M N S T 2} t}{36}}\right]
$$

The previous equation can hence be simplified into a basic form as in Eq. (15)

$$
\begin{aligned}
P_{a c f}^{M N S T S} & =\frac{1}{\eta}\left[\frac{3}{2} \pi^{1 / 2} \sigma_{0} t^{3 / 2} B_{N S T 2}^{1 / 2}+\frac{3}{2} \pi^{1 / 2} \sigma_{0} t^{3 / 2} B_{N S T 2}^{1 / 2}\right] \\
& =\frac{3}{\eta}\left(\pi^{1 / 2} \sigma_{0} t^{3 / 2} B_{N S T 2}^{1 / 2}\right)
\end{aligned}
$$

Where $B_{M N S T 2}=B_{1}+B_{2}=(4 a-4 t)+\left(4 a_{1}-4 t\right)$

\subsection{Extracting $\boldsymbol{P}_{\boldsymbol{a c f}}$ for MNST3 structure}

The MNST3 structure consists of three tubes and thus it contains 12 corner elements. The works of [40], [41] showed that the membrane energy of the right corner of a single tube deformed in extensional mode is as stated in Eq. (5). Considering that the tubes of MNST3 have different sizes and due to interaction among them during the crushing, the membrane area at hinge lines of the outer tube is bigger than that of the middle inner tube and the membrane area of the middle tube is bigger than that of the inner one. Undoubtedly, it is not possible to determine these membrane areas accurately. According to the suggestion in the section 3.2, the membrane areas at corner elements of the inner, middle, and outer tubes are assumed to be $2 H^{2}, 2.5 H^{2}$, and $3 H^{2}$, respectively. Then, the membrane energy at corners of tubes are as follows 


$$
\begin{aligned}
& E_{m-2^{n d} \text { inner tube }}^{M N S T 3}=8 M_{0} \frac{H^{2}}{t} \\
& E_{m-1^{s t} \text { innertube }}^{M N S T 3}=10 M_{0} \frac{H^{2}}{t} \\
& E_{m-\text { outer tube }}^{M N S T 3}=12 M_{0} \frac{H^{2}}{t}
\end{aligned}
$$

Replacing the bending and membrane energy into Eq. (2) yields the relation as follows

$$
\begin{aligned}
P_{a c f}^{M N S T 3} 2 H \eta & =\left[E_{b}^{M N S T 3}+E_{m}^{M N S T 3}\right] \\
& =\left[2 \pi M_{0}\left(B_{1}+B_{2}+B_{3}\right)+4\left(8 M_{0} \frac{H^{2}}{t}+10 M_{0} \frac{H^{2}}{t}+12 M_{0} \frac{H^{2}}{t}\right)\right]
\end{aligned}
$$

where $B_{1}, B_{2}$, and $B_{3}$ are the widths of the inner, middle, and outer tubes, respectively Eq. (17) is then taken a general form

$$
\frac{P_{a c f}^{M N S T 3} \eta}{M_{0}}=\frac{\pi\left(B_{1}+4 B_{2}+B_{3}\right)}{H}+2\left(30 \frac{H}{t}\right)=\frac{\pi B_{M N S T-3}}{H}+60 \frac{H}{t}
$$

The wavelength $H$ in Eq. (18) is calculated by invoking the stationary condition $\partial P_{m} / \partial H=0$ which results in $\mathrm{H}$ as follow

$$
H=\sqrt{\frac{\pi B_{M N S T-3} t}{60}}
$$

Introducing Eq. (19) into Eq. (18) gives the general formula for $P_{a c f}$ of MNST3 structure

$$
P_{a c f}^{M N S T 3}=\frac{1}{\eta}\left[\pi \frac{\sigma_{0} t^{2}}{4} B_{M N S T-3} \sqrt{\frac{60}{\pi B_{M N S T-3} t}}+60 \frac{\sigma_{0} t^{2}}{4} \frac{1}{t} \sqrt{\frac{\pi B_{M N S T-3} t}{60}}\right]
$$

The alternative form of Eq. (20) is rewritten as

$$
P_{a c f}^{M N S T 3}=\frac{\sqrt{3.75}}{\eta}\left(\pi^{1 / 2} \sigma_{0} t^{3 / 2} B_{M N S T 3}^{1 / 2}\right)
$$

in which $B_{M N S T-3}=B_{1}+B_{2}+B_{3}=(4 a-4 t)+\left(4 a_{1}-4 t\right)+\left(4 a_{2}-t\right)$

\subsection{Extracting $\boldsymbol{P}_{\boldsymbol{a c f}}$ for all structures under dynamic loading}

The previously extracted expressions for $P_{a c f}$, as shown in formulae (10), (15), and (21), have not reckoned with the influence of the dynamic loading and thus they are only applicable to structures under quasi-static loads [12]. For impact loading case, the crushing load of the nested 
tubes structures should be augmented due to dynamic effects which can be expressed by a dynamic coefficient $(\lambda)$. This coefficient is proposed to consider inertia and material strain rate effects as well as the interaction among tubes of the nested systems. However, for aluminium alloy used in this study, the material strain rate effects can be ignored as it is insensitive to strain rate under dynamic load [42]. The dynamic coefficient $(\lambda)$ is the ratio between average collapsing load under dynamic and average collapsing load under quasi-static loading, as it can be shown in equation 22

$$
\lambda=\frac{P_{a c l}^{d y n}}{P_{a c l}^{q u a s}}
$$

To calculate $\lambda$ for the different structures studied in this paper, quasi-static and dynamic numerical simulations were conducted. The quasi-static and dynamic force-displacement responses are shown in Fig.6. The calculated $\lambda$ was found to be 1.2, 1.22, and 1.03 for TSST, MNST2, and MNST3, respectively. These values for $\lambda$ are in agreement with those reported in [36].

Fig. 6. Quasi-static and dynamic force-displacement curves for the different structures

In this manner, the formulas to estimate the dynamic $P_{a c f}$ for all structures subjected to axial impact loading are as follows

For TSST structure

$$
P_{a c f-d y n .}^{T S S T}=\lambda_{1} P_{a c f}^{T S S T}=\frac{1.2}{0.7}\left(2 \pi^{1 / 2} \sigma_{0} t^{3 / 2} B_{S S T}^{1 / 2}\right),
$$

For MNST2 structure

$$
P_{a c f-d y n .}^{M N S T 2}=\lambda_{2} P_{a c f}^{M N S T S}=\frac{1.22}{0.7}\left(\sqrt{8} \pi^{1 / 2} \sigma_{0} t^{3 / 2} B_{N S T 2}^{1 / 2}\right)
$$

For MNST3 structure

$$
P_{\text {acf }-d y n .}^{M N S T 3}=\lambda_{3} P_{a c f}^{M N T 3}=\frac{1.03}{0.7}\left(\sqrt{18} \pi^{1 / 2} \sigma_{0} t^{3 / 2} B_{M N S T 3}^{1 / 2}\right)
$$

\subsection{Validation of theoretical relations}

To validate the theoretical models developed in the previous section, numerical analyses using LSDYNA were conducted for all structures where the average collapse force were calculated from the simulations and compared to that obtained from theoretical relations. The comparison 
of $P_{a c f}$ obtained from theoretical models, i.e. by using equations 23,24 , and 25 for TSST, MNST2, and MNST3, respectively, and numerical simulations is given in Table 3. As it can be seen from this table, the theoretical predictions of $\mathrm{P}_{\text {acf }}$ compare fairly well with those obtained from the numerical simulations for all structures.

To further validate the theoretical model, the result obtained from the theoretical solution is compared with that obtained from experiment reported in [36]. The force-displacement response and crushing behaviour of MSSQ is shown in Fig. 11 which shows clearly that most of structure deformation and hence the energy absorption takes place principally in the middle and outer tubes of the structure. The gap size between middle and outer tubes of the MSSQ is equal to that in MNST2-1 structure. Furthermore, the masses of these two structures are identical and thus the theoretical expression used to calculate average collapse force ( $\left.\mathrm{P}_{\mathrm{acf}}\right)$ of MNST2-1, Eq. 23, can be used to estimate $P_{a c f}$ for MSSQ structure. The experimental $P_{a c f}$ for MSSQ was estimated from the force-displacement curve as presented in Fig.11. The comparison between the theoretical and experimental $P_{a c f}$ for MSSQ structure is also presented in Table 3. It can be seen that the theoretical $P_{a c f}$ is in excellent agreement with the experimental one.

Table 3. Average Crush Force $\left(\boldsymbol{P}_{\boldsymbol{a c f}}\right)$ of all structures

4. Further discussion and evaluation of energy absorption characteristics

To make a valid comparison of the energy absorption characteristics, the mass of the compared structures should be same. Among the various structures used to validate the theoretical models, as presented in Table 1, the dimensions of TSST MNST2-2, MNST2-3, MNST2-5, MNST3-2, MSSQ were selected as such they yield same mass for these tubes. The deformation modes and load-displacements curves for these structures are shown in Figs 7-12. It is clear that the deformation mode of TSST, MNST2, MNST3, and MSSQ structures are progressive collapse mode and none of them experience the inefficient global bending mode. It is well reported in the literature that the progressive collapse with stable deformation provides higher energy absorption efficiency than global bending mode because the latter induces an unstable collapse with a restricted plastic deformation in a limited region of the structure [2]. 
From a manufacturing perspective, the nested structures including MNST2 and MNST3 are relatively easier to be produced than the tailor-cut structures, including TSST and MSSQ, where the latter contain holes that are not easy to be prepared and need special cutting tools.

Fig. 13 compares the Peak Crush Force (PCF) and Specific Energy Absorption (SEA) responses of those structures which have same weight. Overall, the energy absorption indexes of MNST2-2 are greater than those of the other structures. This observation can be attributed to the interaction effects between the various components of this structure, i.e. inner and outer tubes, during the crushing process. The interaction effects means that the average crush force of a nested structure is larger than the sum of the average crush forces of its tubes when they are crushed separately [42]. During the progressive collapse of the nested structures, a contact between the components of these structures is occurred which in turn might affect the deformation modes of these tubes. The extent of the contact effect depends mainly on the dimensions of the tubes that form the nested structures. For MNST2 structure, the interaction effects between the inner and outer tubes are related to size of the gap between the two tubes. As it can be seen from Fig. 13, MNST2-2, which has the smallest gap, demonstrates the greatest energy absorption capacity whereas MNST2-5, which has the biggest gap, exhibits the smallest capacity in terms of energy absorption. In consequence, it can be stated that the smaller the gap between two tubes is, the larger the energy absorption of the structure is. This could be due to the fact that the smaller gap allows for greatest contact between the tubes during the defamation as it can be seen from Fig. 14. When the gap is smaller, the contact between the walls of the tubes takes place during the early stages of loading resulting in greater contact area between the walls of the tubes. Once the contact between the tubes is established, the outer tube then constitutes a sort of resistance for the buckling of the inner tube and this decreases the wavelength of the sidewalls of the tubes leading to an increase in number of lobes. It is clear from Fig. 14 that the tubes of MNST2-5 were almost deformed independently from each other and no evidence of contact between them was observed during the loading. On the other side, contact and interaction can clearly be observed in case of MNST2-2 and MNST2-3 which in turn enhanced the energy absorption behaviour of these structures over the MNST2-5. Given that the MNST3-2 structure consists of three components, it was expected that the energy absorption enhancement resulted from the interaction effects is greater in this structure. However, as it can be seen from Fig 13, the MNST3-2 structure does not offer the greatest SEA and this could be due to fact that its 
components, i.e. the inner, middle, and outer tubes, are thinner than that the components used to construct MNST2-2 structure. The thinner components of MNST3-2 structures were unable to create the sufficient resistance to alter the deformation pattern of the other components and for this the energy absorption enhancement due to interaction effects was limited in this structure. In terms of Peak Crush Force (PCF), MNST3 offers the lowest PCF among all studied structures whereas TSST exhibits the highest magnitude of PCF. This can be attributed to the fact that the inner tube of MNST3 has the smallest thickness and the TSST has the greatest thickness among the other structures. Generally, PCF magnitude depends on the type of the trigger. In the nested structures, the inner tubes were used as trigger so the thickness of the inner tube is the most dominating factor for PCF. For the tailor-cut structures, the PCF is greatest in TSST which was decreased in MSSQ structure but it still higher than that offered by MNST3.

In order to determine the best performing energy absorbing structure among those presented in Fig 13, a multi-criteria decision making method known as the Technique of Order Preference by Similarity to Ideal Solution (TOPSIS) was employed with SEA and PCF responses as design criteria [43]-[45]. The step by step application of this technique is provided elsewhere [45], [46]. The final score and ranking of each structure obtained via TOPSIS method are presented in the Table 5. The results show that by considering all crashworthiness metrics, the nested structures consisted of three components, i.e. MSSQ and MNST3, are the best structures for energy absorbing applications because they offer low PCF with relatively high SEA.

Fig. 7. a) Crushing behaviour; (b) load-displacement curve; and (c) energy absorption of the TSST Fig. 8. a) Crushing behaviour; (b) load-displacement curve; and (c) energy absorption of the MNST2-1 Fig. 9. a) Crushing behaviour; (b) load-displacement curve; and (c) energy absorption of the MNST2-2 Fig. 10. a) Crushing behaviour; (b) load-displacement curve; and (c) energy absorption of the MNST2-3

Fig. 11. a) Crushing behaviour; (b) load-displacement curve; and (c) energy absorption of the MNST3

Fig. 12. a) Crushing behaviour; (b) load-displacement curve of the MSSQ [32] Fig. 13. Peak Crush Force (PCF) and Specific Energy Absorption (SEA) for all structures Fig. 14. Cut view of the final deformed profile of a) MNST2-1, b) MNST2-2, c) MNST2-3, and d) MNST3

\section{Conclusion}

This study proposes theoretical solutions for Average Crush Force $\left(P_{a c f}\right)$ of the nested and tailorcut energy absorption tubular structures based on the energy method, simple superposition 
principle and interaction among tubes wall. The theoretical models have shown well accordance with numerical and experimental data for all structures. Such theoretical models provide an easy and quick way to evaluate the energy absorption behaviour of the nested tubes structures. The main points that can be reported from this study are as follows:

- The interaction among the components of the nested tubes structures plays an important role in enhancing the energy absorption behaviour of the structure under axial impact loading case.

- The crashworthiness performance of nested tubes structures with higher number of components, i.e. MNST3 and MSSQ, is better than the rest of structures including MNST2 and TSST.

- Among all studied structures, the nested tubes structure with three components, i.e. MNST3, was selected as the best energy absorbing structure because it is exhibited outstanding crashworthiness behaviour as well as it is easier to be created than MSSQ structure. 


\section{References}

[1] G. Lu and T. X. Yu, Energy Absorption of Structures and Materials. Elsevier, 2003.

[2] A. Baroutaji, M. Sajjia, and A.-G. Olabi, "On the crashworthiness performance of thinwalled energy absorbers: Recent advances and future developments," Thin-Walled Struct., vol. 118, pp. 137-163, Sep. 2017.

[3] A. Baroutaji and A. G. Olabi, "Lateral collapse of short-length sandwich tubes compressed by different indenters and exposed to external constraints," Materwiss. Werksttech., vol. 45, no. 5, p. n/a-n/a, May 2014.

[4] A. Baroutaji, M. D. Gilchrist, D. Smyth, and A. G. Olabi, "Crush analysis and multiobjective optimization design for circular tube under quasi-static lateral loading," ThinWalled Struct., vol. 86, pp. 121-131, 2015.

[5] A. Baroutaji, E. Morris, and A. G. Olabi, "Quasi-static response and multi-objective crashworthiness optimization of oblong tube under lateral loading," Thin-Walled Struct., vol. 82, pp. 262-277, Sep. 2014.

[6] A. Baroutaji, M. D. Gilchrist, D. Smyth, and A. G. Olabi, "Analysis and optimization of sandwich tubes energy absorbers under lateral loading," Int. J. Impact Eng., vol. 82, pp. 74-88, Aug. 2015.

[7] T. Tran and T. N. T. Ton, "Lateral crushing behaviour and theoretical prediction of thinwalled rectangular and square tubes," Compos. Struct., vol. 154, pp. 374-384, 2016.

[8] S. R. Reid, "Plastic deformation mechanisms in axially compressed metal tubes used as impact energy absorbers," Int. J. Mech. Sci., vol. 35, no. 12, pp. 1035-1052, Dec. 1993.

[9] C. W. Isaac and O. Oluwole, "Structural response and performance of hexagonal thinwalled grooved tubes under dynamic impact loading conditions," Eng. Struct., vol. 167, pp. 459-470, Jul. 2018.

[10] O. Fyllingen, E. C. Langmoen, M. Langseth, and O. S. Hopperstad, "Transition from progressive buckling to global bending of square aluminium tubes," Int. J. Impact Eng., vol. 48, pp. 24-32, 2012.

[11] Z. Li, H. Yang, X. Hu, J. Wei, and Z. Han, "Experimental study on the crush behavior and energy-absorption ability of circular magnesium thin-walled tubes and the comparison with aluminum tubes," Eng. Struct., vol. 164, pp. 1-13, Jun. 2018.

[12] W. Chen and T. Wierzbicki, "Relative merits of single-cell, multi-cell and foam-filled 
thin-walled structures in energy absorption," Thin-Walled Struct., vol. 39, no. 4, pp. 287306, Apr. 2001.

[13] T. Tran, S. Hou, X. Han, W. Tan, and N. Nguyen, "Theoretical prediction and crashworthiness optimization of multi-cell triangular tubes," Thin-Walled Struct., vol. 82, pp. 183-195, Sep. 2014.

[14] A. A. Nia and S. Chahardoli, "Mechanical behavior of nested multi-tubular structures under quasi-static axial load," Thin-Walled Struct., vol. 106, pp. 376-389, Sep. 2016.

[15] A. Alavi Nia and S. Chahardoli, "Optimizing the layout of nested three-tube structures in quasi-static axial collapse," Thin-Walled Struct., vol. 107, pp. 169-181, Oct. 2016.

[16] S. E. Alkhatib, F. Tarlochan, and A. Eyvazian, "Collapse behavior of thin-walled corrugated tapered tubes," Eng. Struct., vol. 150, pp. 674-692, Nov. 2017.

[17] H. S. Kim, "New extruded multi-cell aluminum profile for maximum crash energy absorption and weight efficiency," Thin-Walled Struct., vol. 40, no. 4, pp. 311-327, 2002.

[18] J. Fang, Y. Gao, G. Sun, N. Qiu, and Q. Li, "On design of multi-cell tubes under axial and oblique impact loads," Thin-Walled Struct., vol. 95, pp. 115-126, Oct. 2015.

[19] T. Tran, S. Hou, X. Han, N. Nguyen, and M. Chau, "Theoretical prediction and crashworthiness optimization of multi-cell square tubes under oblique impact loading," Int. J. Mech. Sci., vol. 89, pp. 177-193, Dec. 2014.

[20] T. Tran and A. Baroutaji, "Crashworthiness optimal design of multi-cell triangular tubes under axial and oblique impact loading," Eng. Fail. Anal., vol. 93, pp. 241-256, Nov. 2018.

[21] E. Morris, A. G. Olabi, and M. S. J. Hashmi, "Analysis of nested tube type energy absorbers with different indenters and exterior constraints," Thin-Walled Struct., vol. 44, no. 8, pp. 872-885, Aug. 2006.

[22] A. G. Olabi, E. Morris, M. S. J. Hashmi, and M. D. Gilchrist, "Optimised design of nested oblong tube energy absorbers under lateral impact loading," Int. J. Impact Eng., vol. 35, no. 1, pp. 10-26, Jan. 2008.

[23] A. G. Olabi, E. Morris, M. S. J. Hashmi, and M. D. Gilchrist, “Optimised design of nested circular tube energy absorbers under lateral impact loading," Int. J. Mech. Sci., vol. 50, no. 1, pp. 104-116, 2008.

[24] A. Baroutaji, M. D. Gilchrist, and A. G. Olabi, "Quasi-static, impact and energy 
absorption of internally nested tubes subjected to lateral loading," Thin-Walled Struct., vol. 98, pp. 337-350, Jan. 2016.

[25] A. Rahi, "Controlling energy absorption capacity of combined bitubular tubes under axial loading," Thin-Walled Struct., vol. 123, pp. 222-231, Feb. 2018.

[26] F. Usta, Z. Eren, H. Kurtaran, H. S. Türkmen, Z. Kazanc1, and Z. Mecitoglu, "Crashworthiness Optimization of Nested and Concentric Circular Tubes Using Response Surface Methodology and Genetic Algorithm," Lat. Am. J. Solids Struct., vol. 15, no. 5, Jun. 2018.

[27] M. Haghi Kashani, H. Shahsavari Alavijeh, H. Akbarshahi, and M. Shakeri, "Bitubular square tubes with different arrangements under quasi-static axial compression loading," Mater. Des., vol. 51, pp. 1095-1103, Oct. 2013.

[28] S. Sharifi, M. Shakeri, H. E. Fakhari, and M. Bodaghi, "Experimental investigation of bitubal circular energy absorbers under quasi-static axial load," Thin-Walled Struct., vol. 89, pp. 42-53, Apr. 2015.

[29] A. Eyvazian, M. K. Habibi, A. M. Hamouda, and R. Hedayati, "Axial crushing behavior and energy absorption efficiency of corrugated tubes," Mater. Des., vol. 54, pp. 10281038, Feb. 2014.

[30] Q. Cheng, W. Altenhof, and L. Li, "Experimental investigations on the crush behaviour of AA6061-T6 aluminum square tubes with different types of through-hole discontinuities," Thin-Walled Struct., vol. 44, no. 4, pp. 441-454, Apr. 2006.

[31] A. Najafi and M. Rais-Rohani, "Mechanics of axial plastic collapse in multi-cell, multicorner crush tubes," Thin-Walled Struct., vol. 49, no. 1, pp. 1-12, 2011.

[32] A. Najafi and M. Rais-Rohani, "Influence of Cross-Sectional Geometry on Crush Characteristics of Multi-cell Prismatic Columns," in Proceedings of the 49th AIAA/ASME/ASCE/AHS/ASC structures, structural dynamics and materials conference, 2008.

[33] V. Jandaghi Shahi and J. Marzbanrad, "Analytical and experimental studies on quasi-static axial crush behavior of thin-walled tailor-made aluminum tubes," Thin-Walled Struct., vol. 60, pp. 24-37, Nov. 2012.

[34] T. Wierzbicki and W. Abramowicz, "On the Crushing Mechanics of Thin-Walled Structures," Journal of Applied Mechanics, vol. 50. pp. 727-734, 1983. 
[35] A. G. Hanssen, M. Langseth, and O. S. Hopperstad, "Static and dynamic crushing of square aluminium extrusions with aluminium foam filler," Int. J. Impact Eng., vol. 24, no. 4, pp. 347-383, 2000.

[36] M. S. Zahran, P. Xue, M. S. Esa, and M. M. Abdelwahab, "A novel tailor-made technique for enhancing the crashworthiness by multi-stage tubular square tubes," Thin-Walled Struct., vol. 122, pp. 64-82, Jan. 2018.

[37] X. Song, G. Sun, G. Li, W. Gao, and Q. Li, "Crashworthiness optimization of foam-filled tapered thin-walled structure using multiple surrogate models," Struct. Multidiscip. Optim., vol. 47, no. 2, pp. 221-231, 2013.

[38] W. Abramowicz and N. Jones, "Dynamic axial crushing of square tubes," Int. J. Impact Eng., vol. 2, no. 2, pp. 179-208, Jan. 1984.

[39] W. Abramowicz, "The effective crushing distance in axially compressed thin-walled metal columns," Int. J. Impact Eng., vol. 1, no. 3, pp. 309-317, Jan. 1983.

[40] T. Tran, S. Hou, X. Han, and M. Chau, "Crushing analysis and numerical optimization of angle element structures under axial impact loading," Compos. Struct., vol. 119, pp. 422435, Jan. 2015.

[41] T. Tran, S. Hou, X. Han, N. Nguyen, and M. Chau, "Theoretical prediction and crashworthiness optimization of multi-cell square tubes under oblique impact loading," Int. J. Mech. Sci., vol. 89, pp. 177-193, Dec. 2014.

[42] L. Aktay, B.-H. Kröplin, A. K. Toksoy, and M. Güden, "Finite element and coupled finite element/smooth particle hydrodynamics modeling of the quasi-static crushing of empty and foam-filled single, bitubular and constraint hexagonal- and square-packed aluminum tubes," Mater. Des., vol. 29, no. 5, pp. 952-962, Jan. 2008.

[43] C. L. (Ching-L. Hwang and K. Yoon, Multiple Attribute Decision Making: Methods and Applications A State-of-the-Art Survey. Springer Berlin Heidelberg, 1981.

[44] C.-L. Hwang, Y.-J. Lai, and T.-Y. Liu, "A new approach for multiple objective decision making," Comput. Oper. Res., vol. 20, no. 8, pp. 889-899, Oct. 1993.

[45] H. Nikkhah, F. Guo, Y. Chew, J. Bai, J. Song, and P. Wang, "The effect of different shapes of holes on the crushing characteristics of aluminum square windowed tubes under dynamic axial loading,” Thin-Walled Struct., vol. 119, no. June, pp. 412-420, 2017.

[46] S. Pirmohammad and S. Esmaeili Marzdashti, "Crashworthiness optimization of 
combined straight-tapered tubes using genetic algorithm and neural networks," ThinWalled Struct., vol. 127, pp. 318-332, Jun. 2018. 


\section{$\underline{\text { Figures }}$}

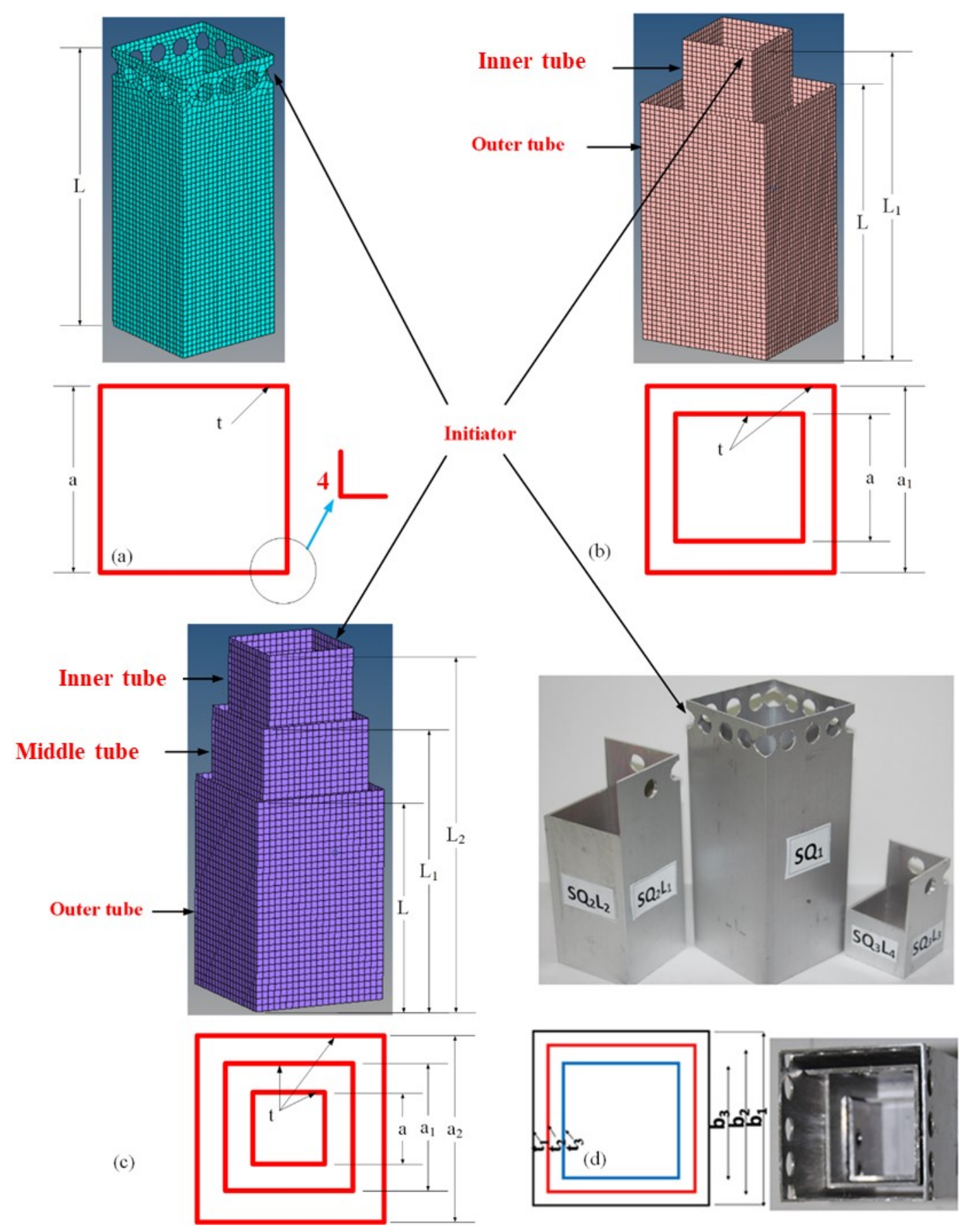

Fig. 1. Geometry of the studied structures: a) Tailored Single Square Tube (TSST), b) Multi Stage Nested Two-Square Tube (MNST2), c) Multi-Stage Nested Three-Square Tube (MNST3), and d) tailored multi-stage nested square tubes (MSSQ) [36] 


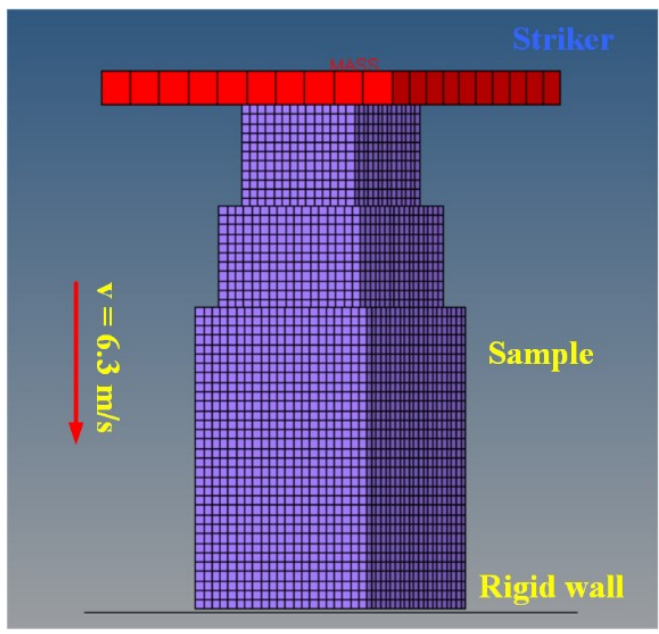

Fig. 2. FE model setup 


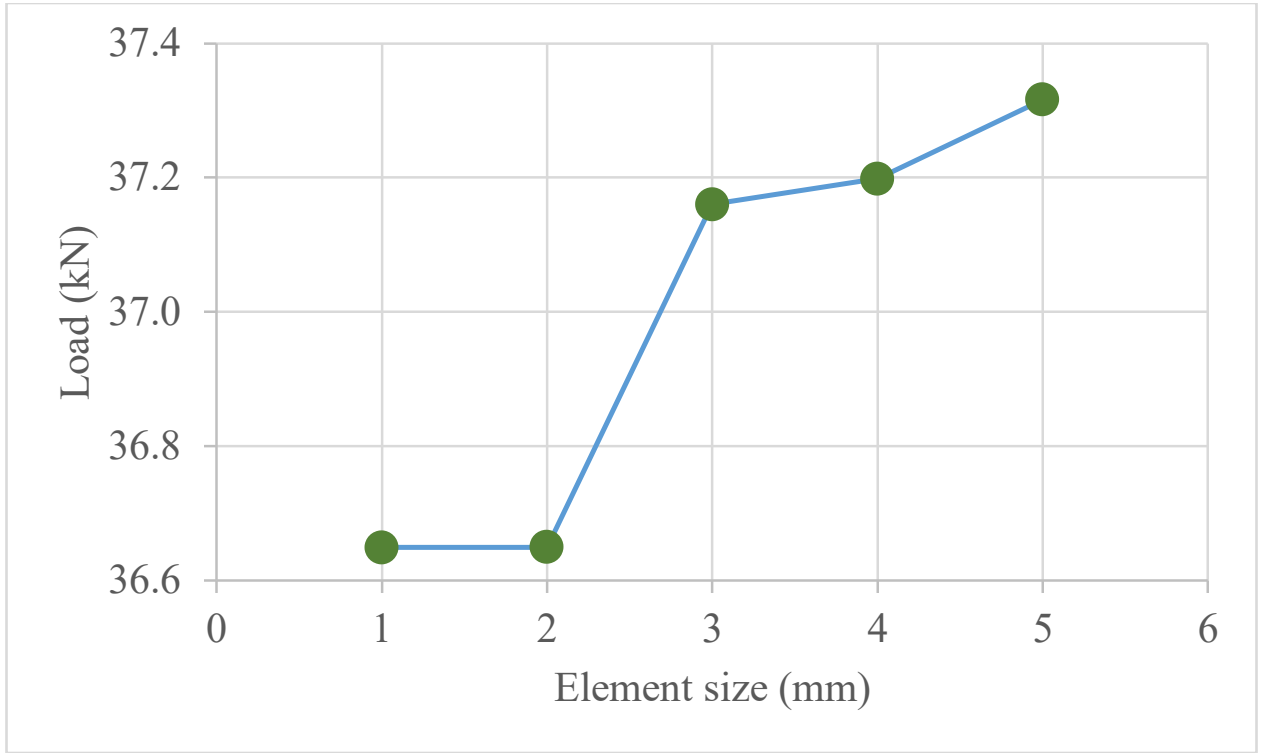

Fig. 3. Convergence of force versus mesh density for square tube. 

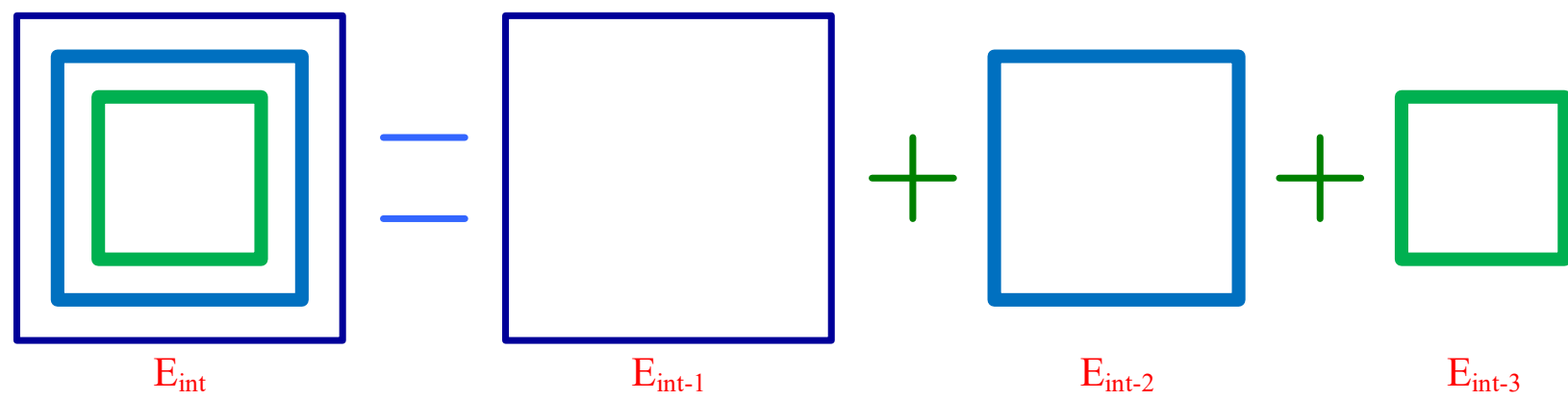

Fig. 4. Simple superposition principle 


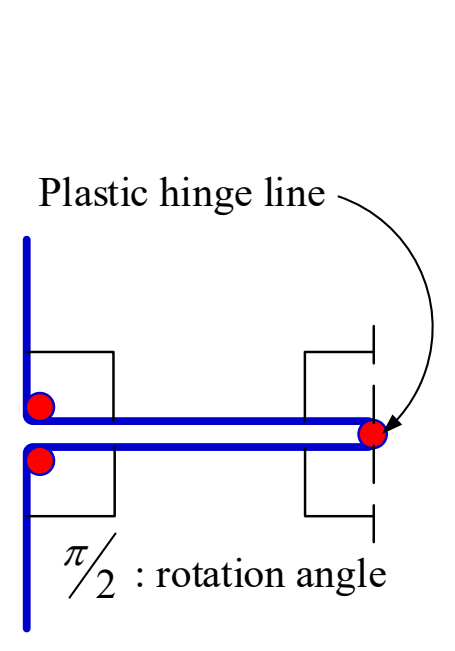

(a)

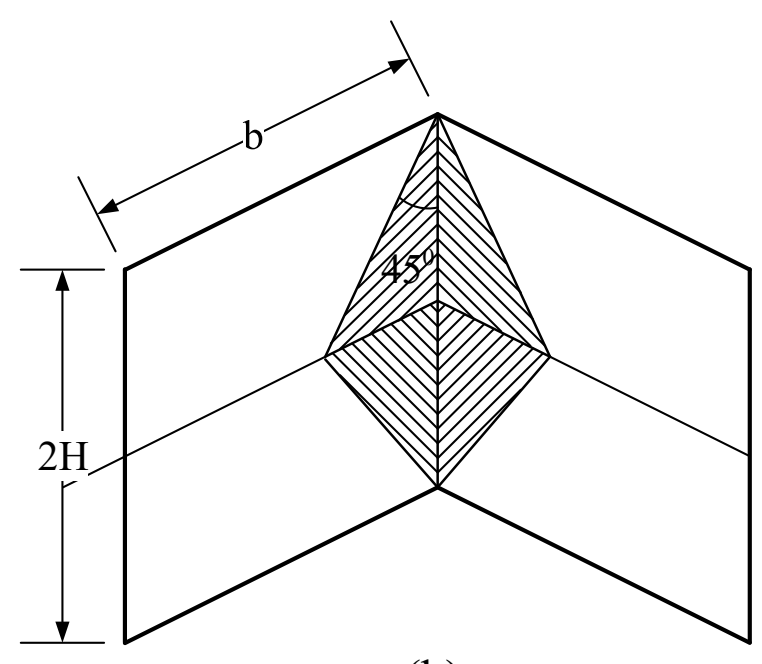

(b)

Fig. 5. Basic folding element: a) rotation angle $(\alpha=2 \pi)$ and plastic hinge line; b) extensional mode 


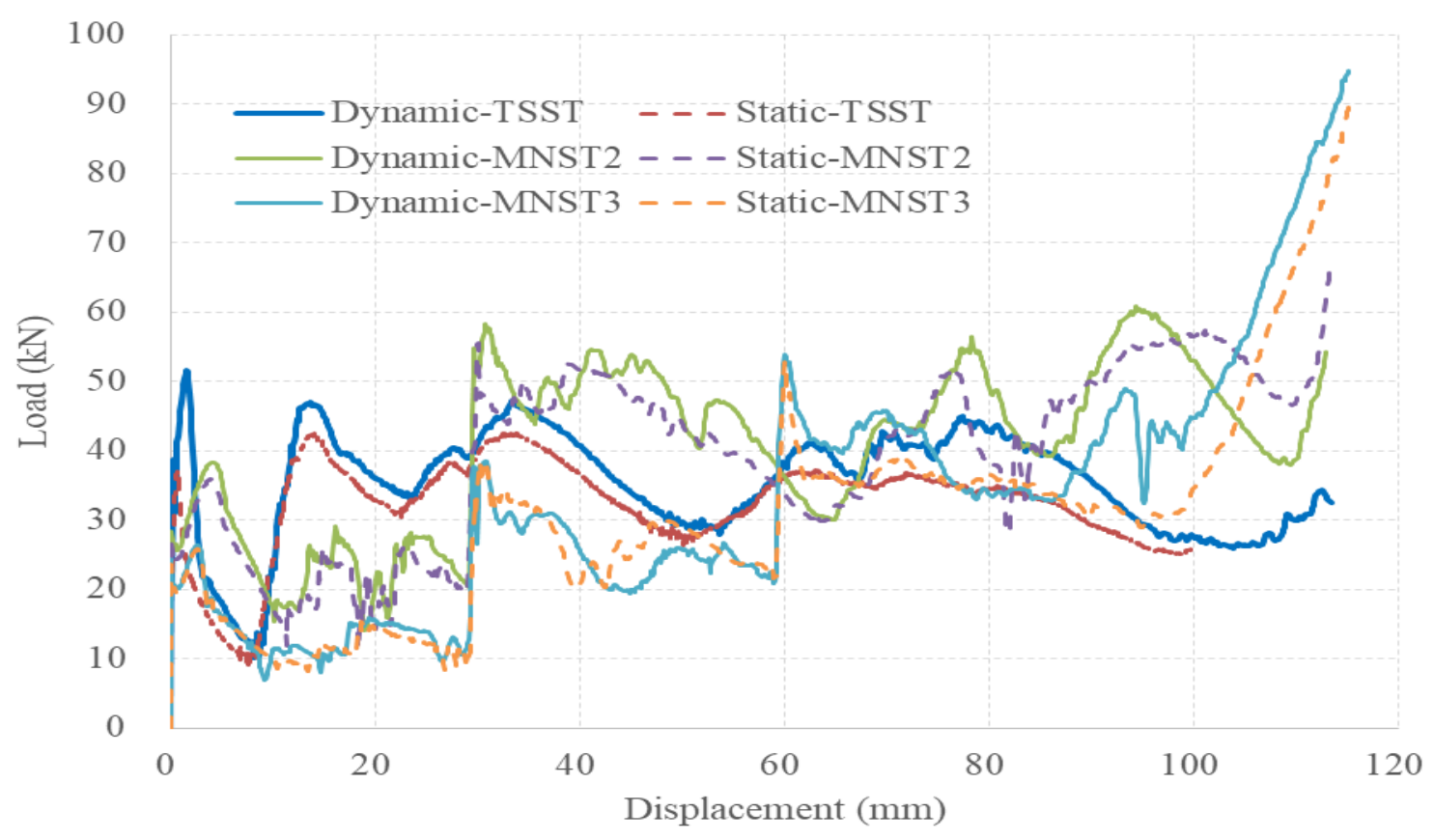

Fig. 6. Quasi-static and dynamic force-displacement curves for the different structures 


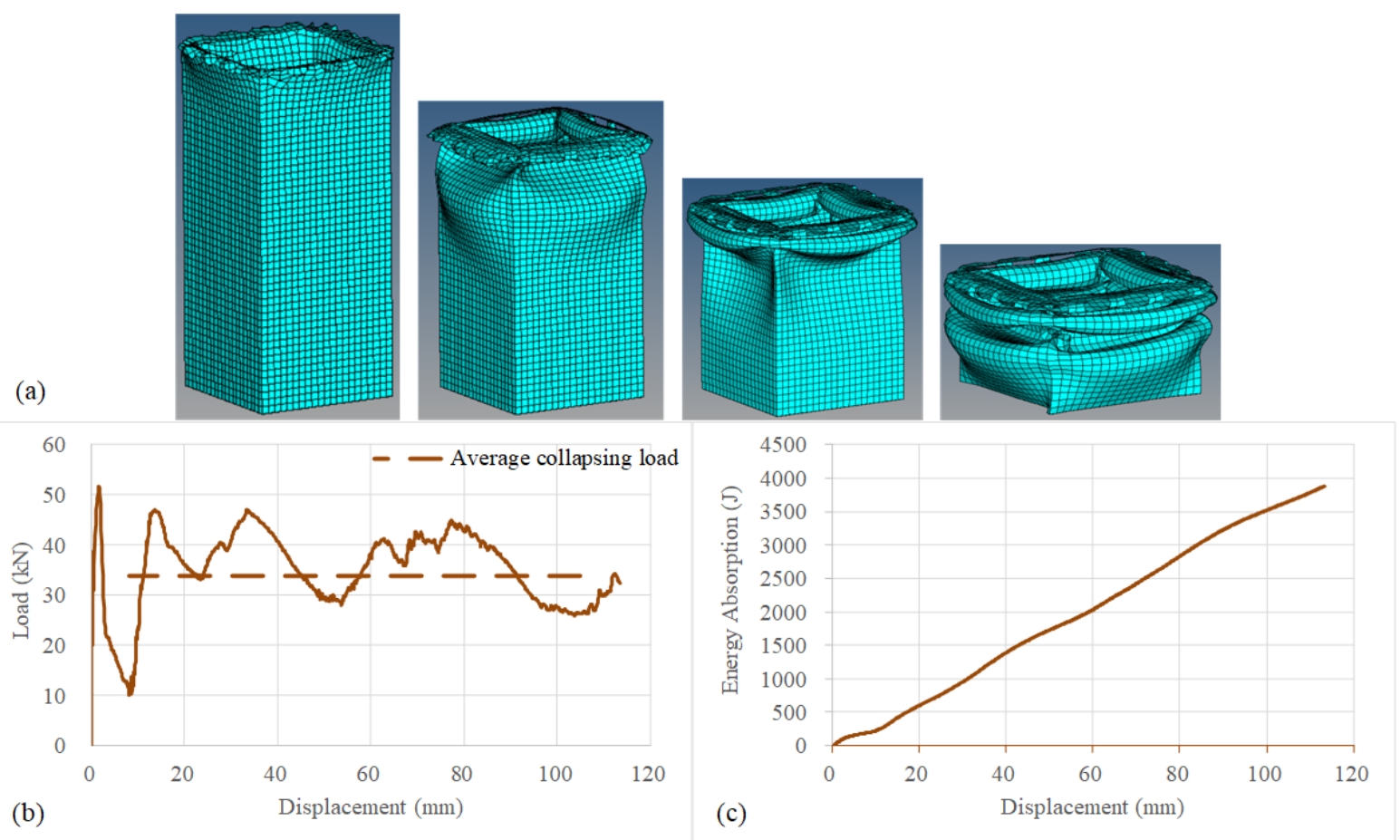

Fig. 7. a) Crushing behaviour; (b) load-displacement curve; and (c) energy absorption of the TSST 


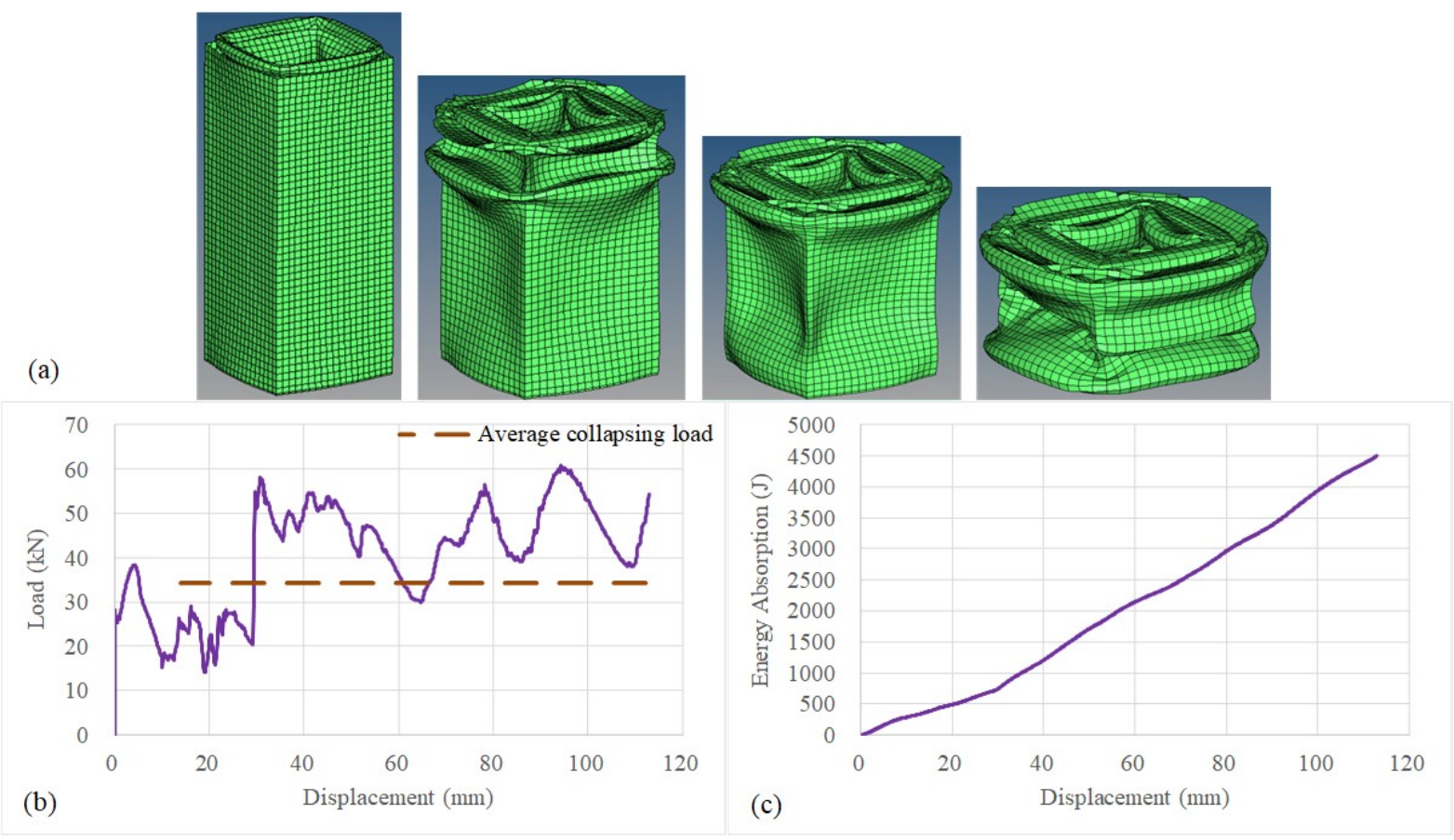

Fig. 8. a) Crushing behaviour; (b) load-displacement curve; and (c) energy absorption of the MNST2-2 


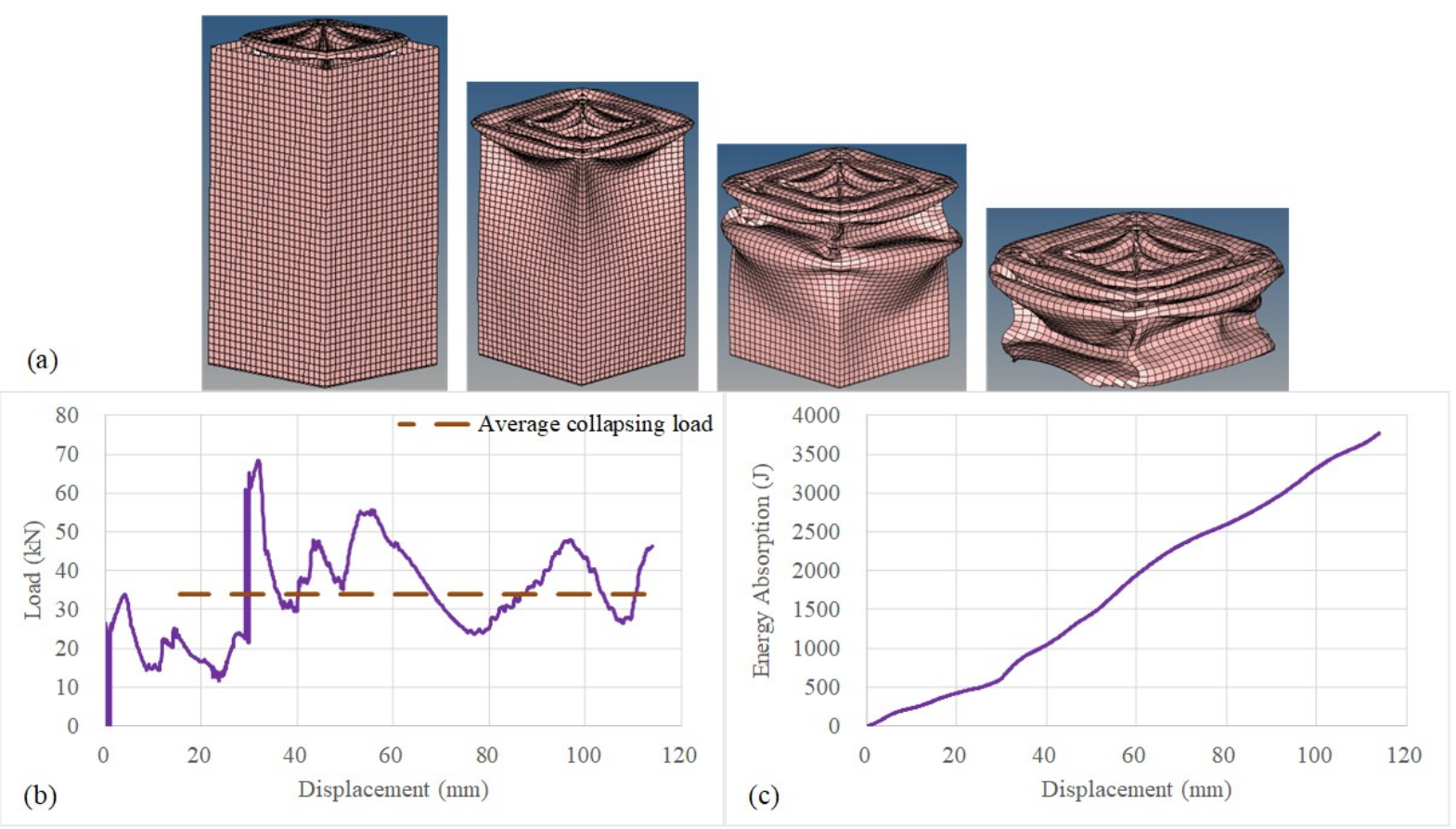

Fig. 9. a) Crushing behaviour; (b) load-displacement curve; and (c) energy absorption of the MNST2-3 


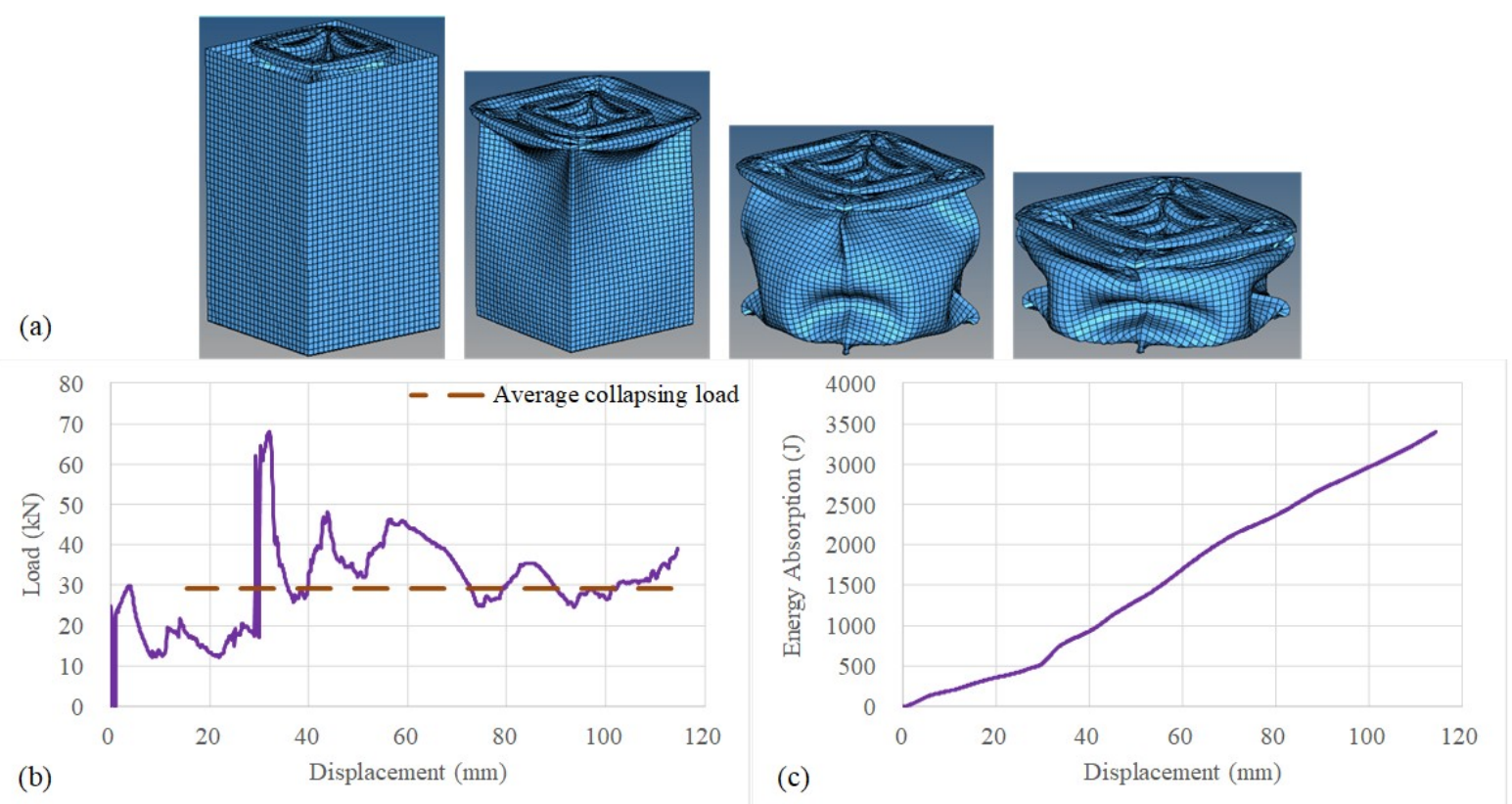

Fig. 10. a) Crushing behaviour; (b) load-displacement curve; and (c) energy absorption of the MNST2-5 


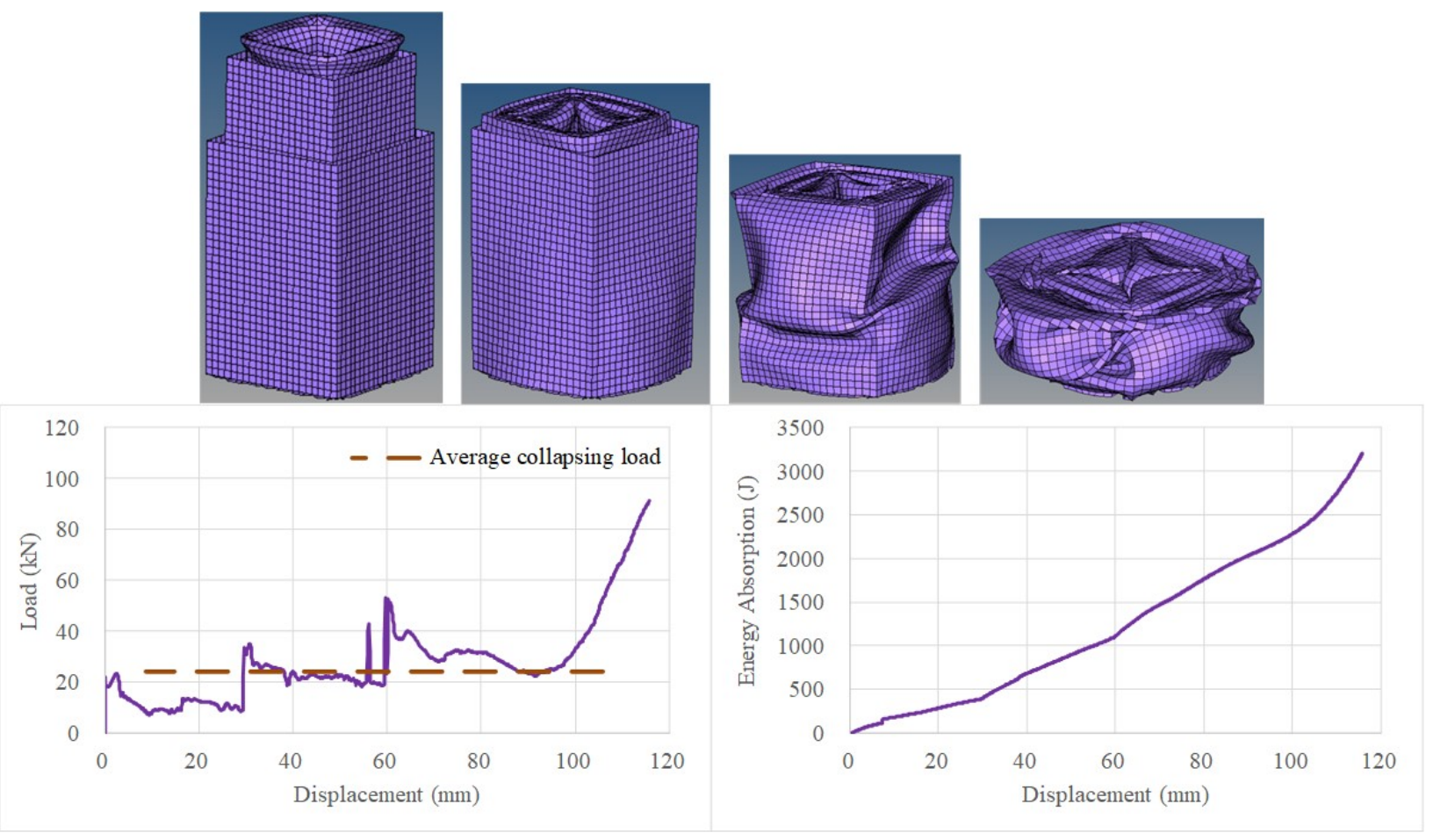

Fig. 11. a) Crushing behaviour; (b) load-displacement curve; and (c) energy absorption of the MNST3-2 


$$
\text { The }
$$




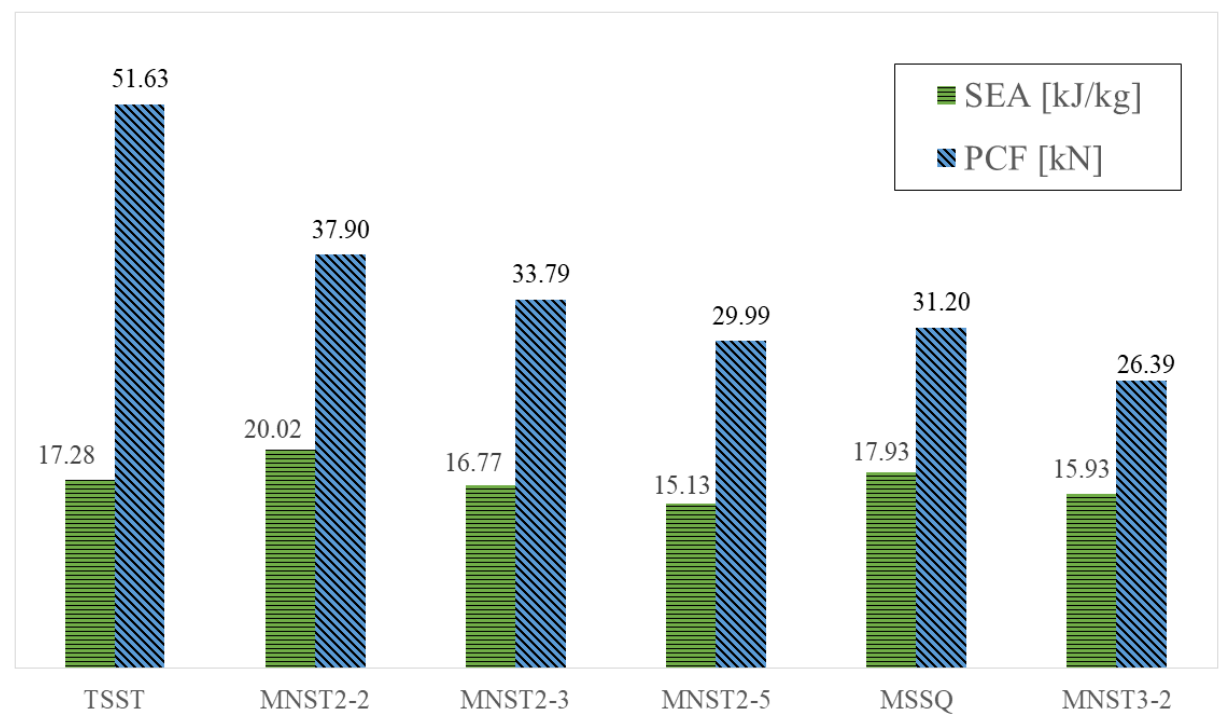

Fig. 13 Numerical Peak Crush Force (PCF) and Specific Energy Absorption (SEA) for structures with same weight 

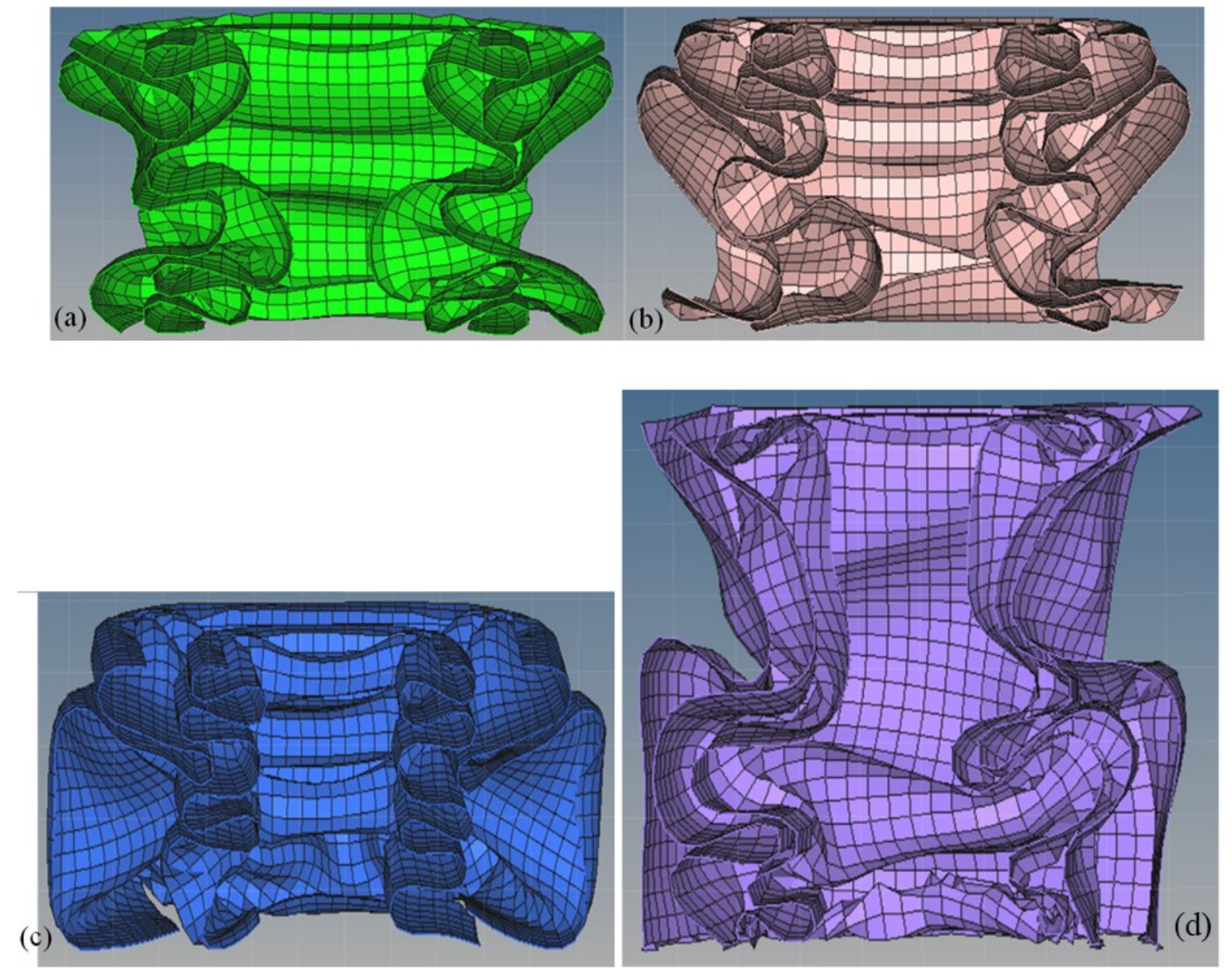

Fig. 14. Cut view of the final deformed profile of a) MNST2-2, b) MNST2-3, c) MNST2-5, and d) MNST3-2 


\section{Tables}

Table 1. Mechanical properties of Aluminium alloy AA6061-O [36]

\begin{tabular}{lr} 
Modulus of Elasticity $(\mathrm{GPa})$ & 68.95 \\
Poisson's ratio, $v$ & 0.32 \\
Mass density, $\rho\left(\mathrm{g} \mathrm{cm}^{-3}\right)$ & 2.7 \\
Initial yield stress, $\sigma_{\mathrm{y}}(\mathrm{MPa})$ & 69.87 \\
Ultimate stress, $\sigma_{\mathrm{u}}(\mathrm{MPa})$ & 136.4 \\
Power law exponent, $\mathrm{n}$ & 0.19 \\
Rupture strain, $\varepsilon_{\mathrm{r}}$ & 0.196 \\
\hline
\end{tabular}


Table 2. Geometrical parameters of all structures

\begin{tabular}{cccccccccc}
\hline & \multicolumn{3}{c}{ FE model configurations' parameters and dimensions (mm) } \\
\cline { 2 - 10 } Structure & \multicolumn{3}{c}{ Outer tube } & \multicolumn{3}{c}{ Inner tube } & \multicolumn{3}{c}{ Middle tube } \\
\cline { 2 - 11 } & $\mathrm{L}$ & $\mathrm{a}$ & $\mathrm{t}$ & $\mathrm{L}_{1}$ & $\mathrm{a}_{1}$ & $\mathrm{t}$ & $\mathrm{L}_{2}$ & $\mathrm{a}_{2}$ & $\mathrm{t}$ \\
\hline TSST & 150 & 60 & 2.5 & - & - & - & - & - & - \\
MNST2-1 & 120 & 50 & 1.808 & 150 & 40 & 1.808 & - & - & - \\
MNST2-2 & 120 & 60 & 1.808 & 150 & 50 & 1.808 & - & - & - \\
MNST2-3 & 120 & 60 & 1.632 & 150 & 40 & 1.632 & - & - & - \\
MNST2-4 & 120 & 80 & 1.632 & 150 & 60 & 1.632 & - & - & - \\
MNST2-5 & 120 & 70 & 1.487 & 150 & 40 & 1.487 & - & - & - \\
MNST2-6 & 120 & 90 & 1.487 & 150 & 60 & 1.487 & - & - & - \\
MNST3-1 & 90 & 65 & 1.1072 & 150 & 45 & 1.1072 & 125 & 55 & 1.1072 \\
MNST3-2 & 90 & 60 & 1.228 & 150 & 40 & 1.228 & 125 & 50 & 1.228 \\
\hline
\end{tabular}


Table 3. Comparison between theoretical, numerical, and experimental values of Average Crush Force $\left(P_{a c f}\right)$ of all structures

\begin{tabular}{cccc}
\hline Structure & $\begin{array}{c}\mathrm{P}_{\mathrm{acf}}(\mathrm{kN}) \\
\text { (Numerical) }\end{array}$ & $\begin{array}{c}\mathrm{P}_{\mathrm{acf}}(\mathrm{kN}) \\
(\text { Experimental })\end{array}$ & $\begin{array}{c}\mathrm{P}_{\mathrm{acf}}(\mathrm{kN}) \\
(\text { Theory })\end{array}$ \\
\hline TSST & 34.550 & - & 32.602 \\
MNST2-1 & 37.070 & - & 37.478 \\
MNST2-2 & 41.211 & - & 41.591 \\
MNST2-3 & 33.371 & - & 34.013 \\
MNST2-4 & 40.203 & - & 40.438 \\
MNST2-5 & 29.946 & - & 31.116 \\
MNST2-6 & 36.611 & - & 36.470 \\
MSSQ & - & 37.652 & 37.478 \\
MNST3-1 & 22.819 & - & 23.955 \\
MNST3-2 & 29.826 & - & 31.247 \\
\hline
\end{tabular}


Table 5. Score and rank of all tubes obtained by TOPSIS method

\begin{tabular}{|l|r|r|}
\hline Structure & \multicolumn{1}{|l|}{ Score } & \multicolumn{1}{|c|}{ Rank } \\
\hline MSSQ & 0.214552 & 1 \\
\hline MNST3-2 & 0.209349 & 2 \\
\hline MNST2-5 & 0.186668 & 3 \\
\hline MNST2-3 & 0.18044 & 4 \\
\hline MNST2-2 & 0.167606 & 5 \\
\hline TSST & 0.041385 & 6 \\
\hline
\end{tabular}

